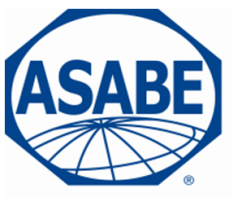

2950 Niles Road, St. Joseph, MI 49085-9659, USA

269.429.0300 fax 269.429.3852 hq@asabe.org www.asabe.org

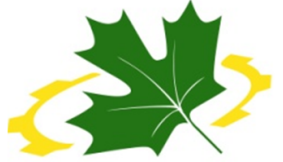

CSBE | SCGAB Paper Number: 1907572.

\title{
Numerical modelling of mirror nozzle flow
}

\author{
Nicolas De Cock ${ }^{1}$, Mathieu Massinon ${ }^{1}$, Benoit C. N. Mercatoris ${ }^{1}$, Frédéric Lebeau ${ }^{1}$ \\ ${ }^{1}$ Université de Liège, Gembloux Agro-Bio Tech, Belgium \\ Written for presentation at the \\ 2014 ASABE and CSBE/SCGAB Annual International Meeting \\ Sponsored by ASABE \\ Montreal, Quebec Canada \\ July 13 - 16, 2014
}

\begin{abstract}
The droplet size distribution of agricultural sprays is a key parameter affecting the efficiency of crop protection product application. The spray quality results from the interactions between physical properties of the liquid, the operating conditions and the nozzle geometry. The present contribution is first step of a work which aims at optimizing the design of mirror nozzle geometry to increase the agricultural spray application efficiency. The optimization will be realized numerically using the multiphase solver InterFoam available in OpenFoam toolbox. For the present paper the quality of the InterFoam solver has been assessed by simulating the impact of a water round jet on a flat plate. The comparison of the numerical prediction with the analytical solution showed a good agreement far from the jet impact. The discrepancies observed could arise from the limitation of the analytical solution close to the jet impact. Then, the solver was used to investigate the sensitivity of a mirror nozzle flow to the inlet geometry and the inlet flow rate. The sensitivity study of the nozzle geometry and the inlet flow rate on the downstream flow allowed us to see a strong effect of both parameters. The flow rate increase lead to a more homogeneous flow for most of the cases. The inlet shape affects significantly the downstream flow. The $140^{\circ}$ circular segment inlet seems suitable for our objective of generating a homogeneous flow on the nozzle plate.
\end{abstract}

Keywords. Computational fluid dynamics, nozzles, spraying, fluid mechanics, crop protection

\section{Introduction}

Nowadays, the use of plant protection products is required to satisfy the demand for agricultural products. During this process the agricultural mixture is atomized by passing through a nozzle generating a cloud of droplets. It has been proved that droplet size has a significant effect on the global deposition process efficiency [12]. Indeed, smaller droplets have a higher drift potential [9] leading to potential product losses in air, water and soil [10]. Whilst, larger droplets, with a higher kinematic energy, are more prone to splash while impacting the target and then may reduce the plant retention efficiency [6].

The droplet sizes and speeds constitutive of a spray result from the interactions between physical properties of the liquid, the operating conditions and the nozzle geometry [7]. During the past decades, multiple researches

The authors are solely responsible for the content of this meeting presentation. The presentation does not necessarily reflect the official position of the American Society of Agricultural and Biological Engineers (ASABE), and its printing and distribution does not constitute an endorsement of views which may be expressed. Meeting presentations are not subject to the formal peer review process by ASABE editorial committees; therefore, they are not to be presented as refereed publications. Citation of this work should state that it is from an ASABE meeting paper. EXAMPLE: Author's Last Name, Initials. 2014. Title of Presentation. ASABE Paper No. ---. St. Joseph, Mich.: ASABE. For information about securing permission to reprint or reproduce a meeting presentation, please contact ASABE at rutter@asabe.org or 269-932-7004 (2950 Niles Road, St. Joseph, MI 49085-9659 USA). 
have been performed on the effect of the liquid physical properties [2] [3] [5] as well as the nozzle type [8]. However, to our knowledge, few specific works focused on the relationship between nozzle geometry parameters and the produced spray. The numerical studies realized on black liquor nozzles provided promising results for nozzle design [4].

The present contribution is the first step of a work which aims at optimizing the design of a mirror nozzle producing a spray with a narrow drop size distribution in order to increase the agricultural spray application efficiency. Mirror nozzles, which generate sprays by the impact of a liquid jet onto a solid surface, offer a low sensibility to clogging and a high customization potential. The optimization will be realized numerically using the open source toolbox of Computational Fluid Dynamics (CFD), OpenFoam. This paper is split in two parts. The first part is dedicated to the verification of the OpenFoam multiphase solver with an analytically solved flow. The second part presents a study of the pipe shape and the inlet flow rate effects on the downstream flow. Emphasis is put on the flow homogeneity at the nozzle exit which is prerequisite for the later work.

\section{Numerical model}

The InterFoam solver from the OpenFoam $\mathrm{C}_{++}$toolbox has been used which is a Volume Of Fluid (VOF) solver for incompressible two-phase flow. The VOF method is used to track and locate the liquid-air interface. It requires an Eulerian grid and the use of an additional variable, $\alpha$. This extra variable defines the liquid fraction inside each cell; its value is equal to 1 for cell full of water, 0 for the cell fill by air and ranging between 0 and 1 while the cell is located at the interface (Figure 1). Then, the interface location is retrieved based on the liquid fraction distribution. This implicit interface capturing method is less accurate than explicit method as level-set but it has the advantage to be mass conservative [1].

\begin{tabular}{|c|c|c|c|c|}
\hline 0.95 & 0.8 & 0.35 & 0.05 & 0 \\
\hline 1 & 1 & 1 & 0.6 & 0.05 \\
\hline 1 & 1 & 1 & 1 & 0.35 \\
\hline 1 & 1 & 1 & 1 & 0.8 \\
\hline 1 & 1 & 1 & 1 & 0.95 \\
\hline
\end{tabular}

Figure 1. Example of $\alpha$ field, the blue shape indicates the real liquid contour.

Here, all the cases are considered in a laminar mode. Therefore, no extra turbulence model has been used. The main equations solved are detailed below, more details about this solver can be found in the paper of Deshpande et al. [1].

The mass conservation for incompressible flow is given by

$$
\nabla \cdot U=0
$$

where $\mathrm{U}$ is the velocity $[\mathrm{m} / \mathrm{s}]$. The liquid fraction transport equation reads

$$
\frac{\partial \alpha}{\partial t}+\nabla \cdot(U \alpha)=0
$$

where $\alpha$ is the liquid fraction and the momentum conservation equation reads

$$
\frac{\partial \rho U}{\partial t}+\nabla \cdot(\rho U U)-\mu \Delta U-\rho g-F_{S T}+\nabla p=0
$$

where $\rho$ is the density $\left[\mathrm{kg} / \mathrm{m}^{3}\right], \mathrm{t}$ is the time $[\mathrm{s}], \mu$ is the dynamic viscosity $[\mathrm{Pa} . \mathrm{s}], \mathrm{g}$ is the gravity $\left[\mathrm{m} / \mathrm{s}^{2}\right], F_{S T}$ is the surface tension force per unit of volume $\left[\mathrm{N} / \mathrm{m}^{3}\right]$ and $p$ is the pressure $[\mathrm{Pa}]$.

The density and the viscosity are computed by weighting the two fluid properties by the liquid fraction as follows

$$
\begin{aligned}
& \rho=\sum \rho_{i} \alpha_{i} \\
& \mu=\sum \mu_{i} \alpha_{i}
\end{aligned}
$$




\section{Test case}

\section{Flow description}

The studied case is the flow created by the impact of a round water jet onto an infinite smooth solid surface (Figure 2). This two-phase flow is close to the mirror nozzle flow. The analysis of this flow by means of boundary-layer theory provides an analytical solution for the free surface height and velocity depending on the jet center distance [11].

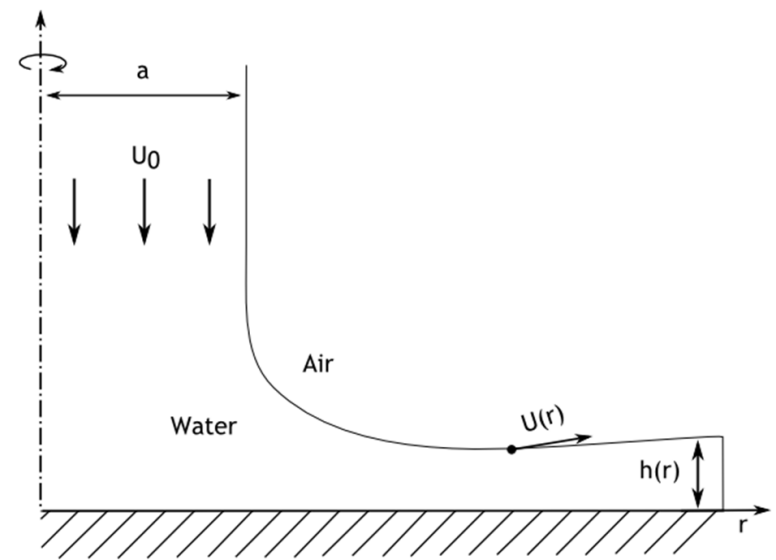

Figure 2. Flow illustration, where $a$ is the jet radius $[\mathrm{m}], U_{0}$ is the initial velocity $[\mathrm{m} / \mathrm{s}], h$ the water thickness $[\mathrm{m}], U$ the velocity magnitude at the water/air interface $[\mathrm{m} / \mathrm{s}]$ and $r$ the distance to the jet center $[\mathrm{m}]$.

For the present contribution, the initial jet velocity and the jet radius are fixed at $3 \mathrm{~m} / \mathrm{s}$ and $0.4 \mathrm{~mm}$ respectively. The jet Reynolds number is computed as follows

$$
R e=\frac{Q}{v a}
$$

where $Q$ is the volumetric flow rate $\left[\mathrm{m}^{3} / \mathrm{s}\right]$ and $v$ is the kinematic viscosity $\left[\mathrm{m}^{2} / \mathrm{s}\right]$. This number is therefore ranging around 1200 .

\section{Numerical parameters}

$$
Q=U_{0} \pi a^{2}
$$

This axisymmetric flow is simulated in OpenFOAM using a wedge shaped mesh. The domain dimensions and the associated boundary conditions are detailed in Figure 3.

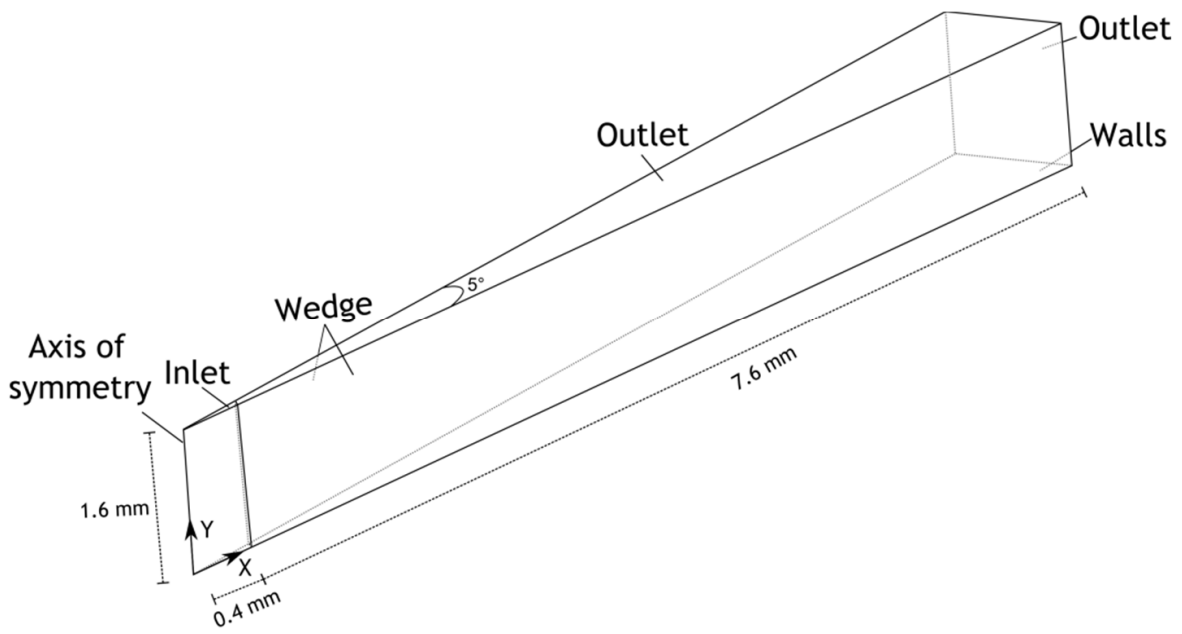

\section{Boundary conditions:}

Inlet: fixed velocity: $U=(0,-3$, $0)$ and fixed liquid fraction: $\alpha=1$.

Walls: no slip condition.

Outlet: fixed pressure: $p=\mathrm{p}_{\text {atm }}$

Wedge: OpenFoam boundary conditions for the front and back plan of an axisymmetric mesh.

Figure 3. Test case numerical domain (left) with the associated boundary conditions (right). 
The mesh generated by the blockMesh utility of OpenFoam is made of hexahedral cells, apart from the cells close to the axis of symmetry which are prismatic, of uniform size. Three mesh refinements have been tested, characteristics of which are presented in Table 1. The grid spacing has been set finer for the $y$ direction which presents higher velocity gradient due to boundary layer development. The simulations have been performed on a desktop computer

Table 1. Mesh characteristics for the three studied cases.

\begin{tabular}{c|cccc|cc}
\hline \hline \multicolumn{4}{c}{ Number of cells } & \multicolumn{2}{c}{ Grid spacing [um] } \\
\hline \hline Case & $\mathbf{X}$ & $\mathbf{Y}$ & $\mathbf{Z}$ & Total & $\mathbf{X}$ & $\mathbf{Y}$ \\
\hline Coarse & 100 & 40 & 1 & 4000 & 80 & 40 \\
\hline Normal & 200 & 80 & 1 & 16000 & 40 & 20 \\
\hline Fine & 400 & 160 & 1 & 64000 & 20 & 10 \\
\hline
\end{tabular}

\section{Comparison of the numerical and the analytical solutions}

The surface velocity and liquid thickness with respect to the radial distance to the jet center are presented on the Figure 4 and 5 respectively. The liquid sheet thickness has been computed as the height at which the liquid fraction is equal to 0.5 . The numerical predictions are in good agreement with the analytical solution for both the height and the surface velocity far from the jet center. However, there are discrepancies between the numerical and the analytical solution for the surface speed prediction close to the jet impact area. These differences could arise from the limitation of the Watson's solution close to the jet impact, where the boundary layer theory cannot be directly applied. A second explanation may be that the too coarse meshes can't resolve correctly the flow in this area where the velocity gradients. However this difference doesn't affect the speed and height prediction further from the jet impact area for the normal and fine mesh cases. The coarse case taking in account its low computational cost provides satisfactory results.

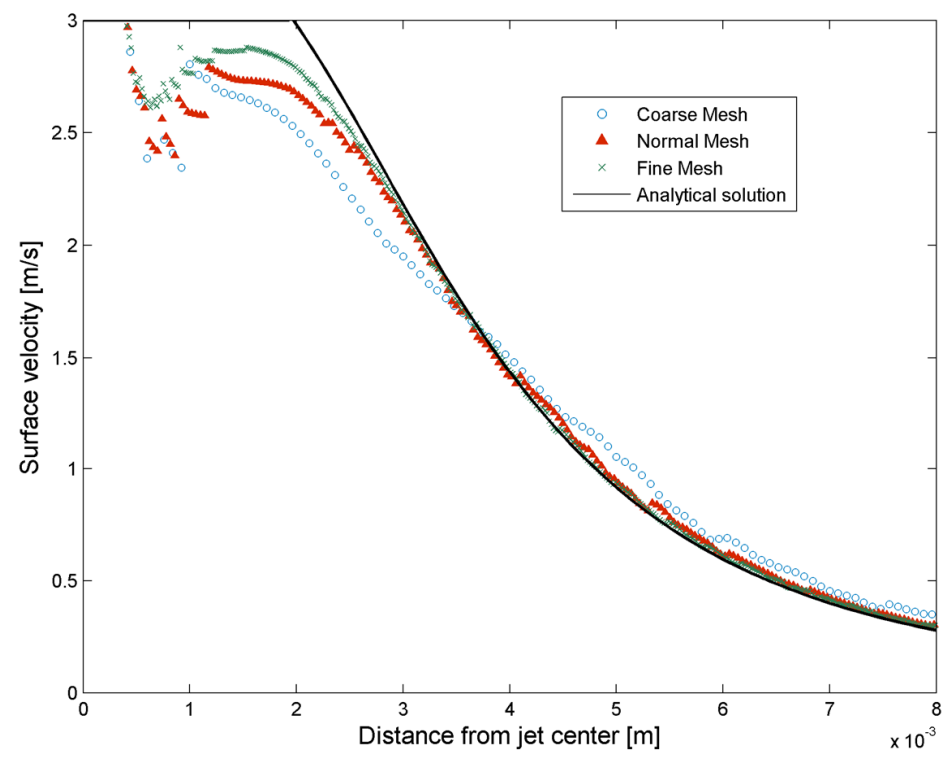

Figure 4. Analytical and numerical solutions of the interface velocity $(U)$ in respect with the radial distance to the jet center $(r)$. 


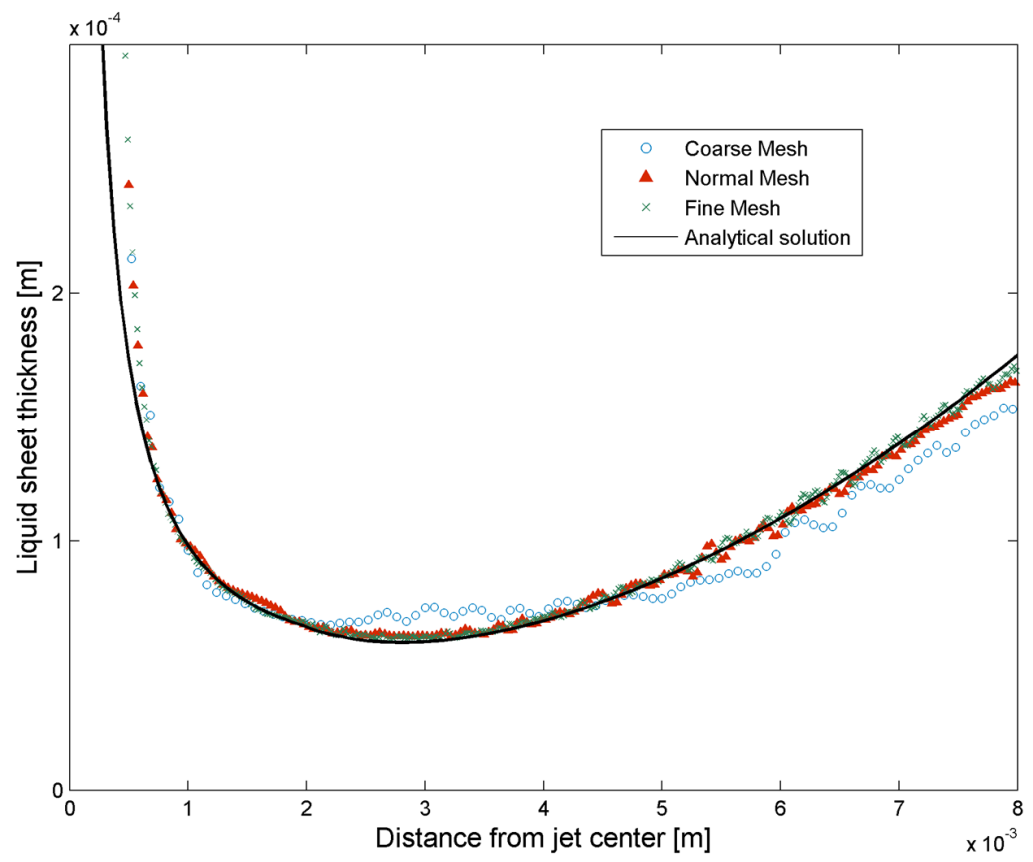

Figure 5. Analytical and numerical solutions of the water thickness $(h)$ in respect with the radial distance to the jet center $(r)$.

\section{Mirror nozzle}

\section{Geometry description}

The goal of the mirror nozzle design is to obtain at the end of the plate a homogeneous liquid sheet making an angle of $\sim 140^{\circ}$. This nozzle is composed by a pipe ending perpendicularly on a flat plate. Over $140^{\circ}$, there is a gap of $0.3 \mathrm{~mm}$ between the plate and the pipe. This opening guides the flow parallel to the plate. The pipe is a circular segment with an opening of $140^{\circ}$ or $180^{\circ}$ for the geometry 1 or 2 respectively. For both geometries, three flow rates are tested: $0.5,1$ and 2 liter per minute (Table 2).

Table 2. Summary of the performed numerical simulations

\begin{tabular}{c|c|c|c}
\hline \hline Case & \multicolumn{1}{c}{ Geometry } & Flow rate [l/min] & Inlet velocity [m/s] \\
\hline 1 & $180^{\circ}$ & 0.5 & 1.05 \\
\hline 2 & $180^{\circ}$ & 1 & 2.10 \\
\hline 3 & $180^{\circ}$ & 2 & 4.2 \\
\hline 4 & $140^{\circ}$ & 0.5 & 1.35 \\
\hline 5 & $140^{\circ}$ & 1 & 2.7 \\
\hline 6 & $140^{\circ}$ & 2 & 5.4 \\
\hline
\end{tabular}

\section{Numerical simulations}

The Figure 6 presents the numerical domain for the geometry 1 with the boundary conditions used for all the simulations. All the simulations were ran as unsteady with the InterFoam solver. At the beginning of the simulations, the flow presents a transient phase during which the plate is progressively wet. The duration of this phase range from 10-40 ms according to the initial flow rate in the pipe (Figure 7). This phase is followed by an almost steady phase. The results presented below (Table 3 ) are the time average of the numerical solution during the steady phase. 
a)

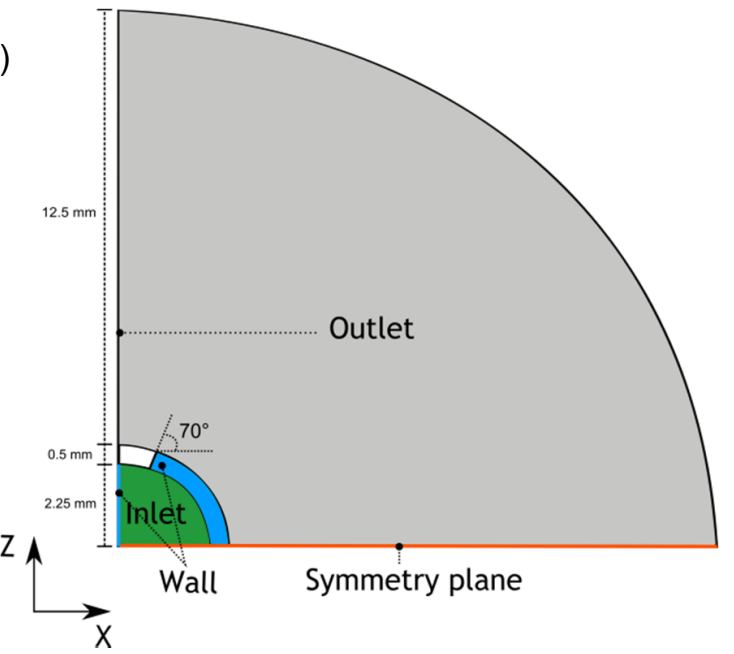

b)

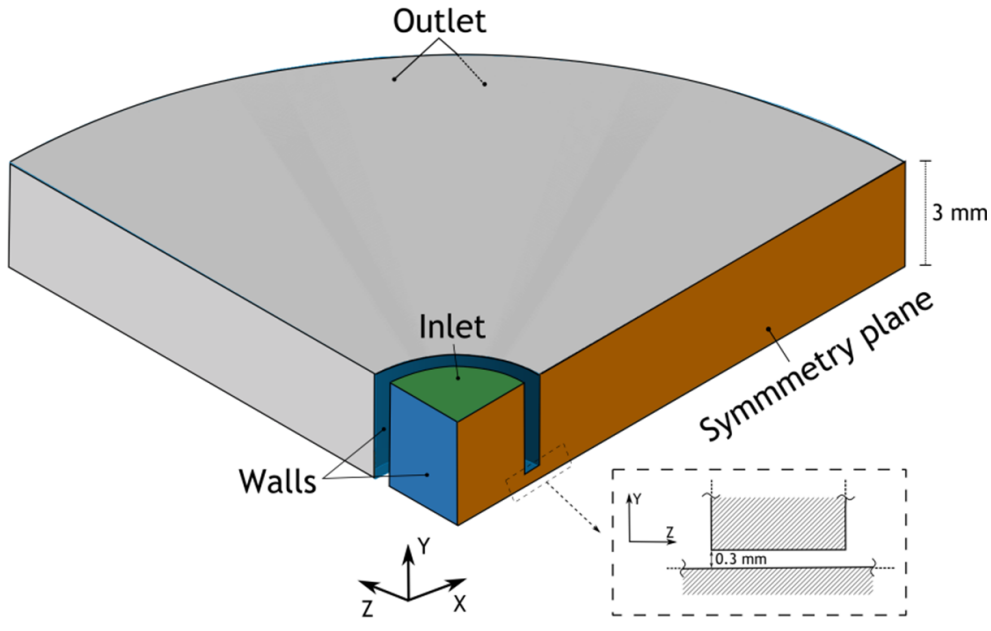

Figure 6. Numerical domain of the geometry 1 with the associated boundary conditions. The top view is presented on the left and an oblique view is presented on the right. The bottom face of the domain is entirely set as wall.
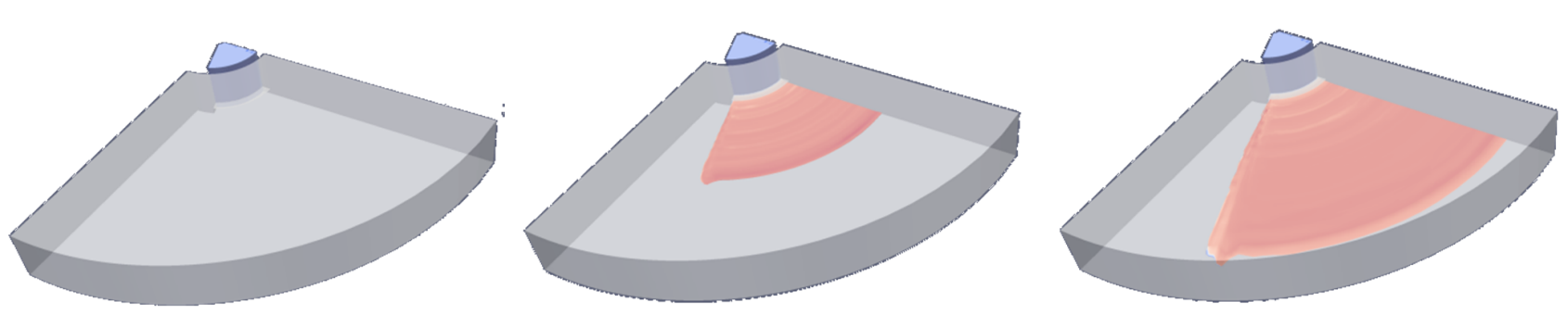

Figure 7. Flow on the plate after 0,2 and $4 \mathrm{~ms}$ respectively for the $140^{\circ}$ pipe with an inlet flow of $2 \mathrm{l} / \mathrm{min}$. The color indicates the surface velocity.

The Table 3 presents the spatial distribution of the normalized water flow rate in the radial direction. The flow is normalized at each position by the inlet flow and the distance from the inlet center. Therefore, for an ideal case the flow rate would be 1 between 0 and $70^{\circ}$.

For all the cases, the water flows radially in respect with the inlet. This behavior validates the choice of mirror nozzle to generate a homogeneous radial flow. The $140^{\circ}$ geometry presents a more homogenous flow rate distribution than the $180^{\circ}$ geometry for the 1 and $2 \mathrm{l} / \mathrm{min}$ cases. The increase of flow rate produces antagonist effects for each geometry. The $140^{\circ}$ case, the flow is becoming more homogeneous leading to an increasing of the flow angle. The $180^{\circ}$ case, from 1 to $2 \mathrm{l} / \mathrm{min}$ the flow becomes less homogeneous inducing a decrease of the flow angle. 
Table 3. Spatial distribution over the plate of the normalized flow rate for each case. The color correspond to the normalized flow rate in the radial direction and the vectors to the average velocity in the liquid phase.

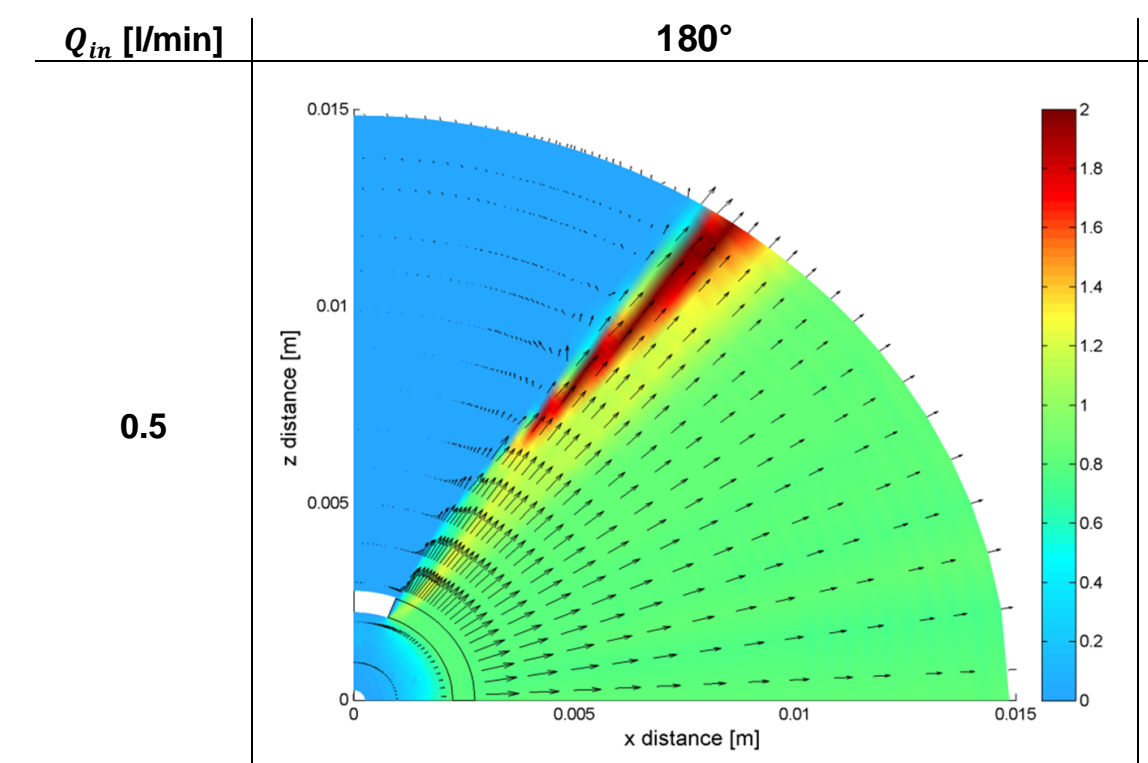

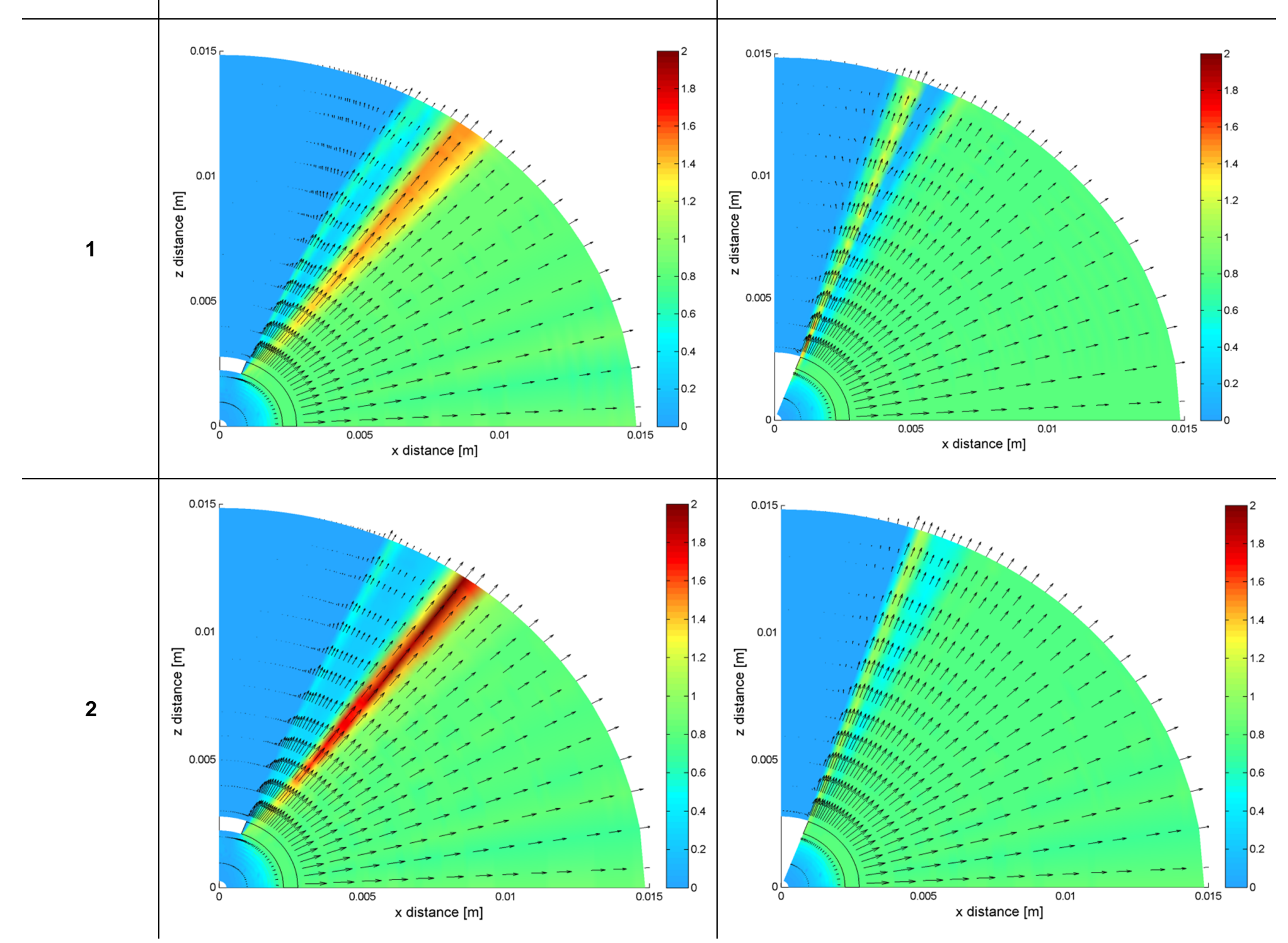




\section{Conclusion}

The InterFoam solver assessment with an analytical provides satisfactory results. The predictions of both liquid sheet height and interface velocity were in good agreement with the analytical solution for the region far from the jet impact. The discrepancies observed in the region close to the impact could arise from the limitation of the analytical solution close to the jet impact. The sensitivity study of the nozzle geometry and the inlet flow rate on the downstream flow allowed us to see a strong effect of both parameters. The flow rate increase lead to a more homogeneous flow for most of the cases. The inlet shape affects significantly the downstream flow. The $140^{\circ}$ circular segment inlet seems suitable for our objective of generating a homogeneous flow on the nozzle plate.

Further works will focus on the experimental validation of the numerical simulations by measurements of liquid sheet and velocity.

\section{Acknowledgements}

I would like to thank the FNRS for the funding of my research through a FRIA grant.

\section{References}

\section{Journal Article}

[1] Deshpande, S. S., Anumolu, L., \& Trujillo, M. F. (2012). Evaluating the performance of the two-phase flow solver interFoam. Computational Science \& Discovery, 5(1), 014016. http://dx.doi.org/10.1088/1749-4699/5/1/014016

[2] Ellis, M. C., Tuck, C. R., \& Miller, P. C. H. (1997). The effect of some adjuvants on sprays produced by agricultural flat fan nozzles. Crop protection, 16(1), 41-50. http://dx.doi.org/10.1016/S0261-2194(96)00065-8

[3] Ellis, B., Tuck, C. R., \& Miller, P. C. H. (2001). How surface tension of surfactant solutions influences the characteristics of sprays produced by hydraulic nozzles used for pesticide application. Colloids and Surfaces A: Physicochemical and Engineering Aspects, 180(3), 267-276. http://dx.doi.org/10.1016/S0927-7757(00)00776-7

[4] Fard, M. P., Levesque, D., Morrison, S., \& Ashgriz, N. (2007). Characterization of splash-plate atomizers using numerical simulations. Atomization and Sprays, 17(4).10.1615/AtomizSpr.v17.i4.30

[5] Holloway, P. J., Ellis, B., Webb, D. A., Westem, N. M., Tuck, C. R., Hayes, A. L., \& Miller, P. C. H. (2000). Effects of some agricultural tank-mix adjuvants on the deposition efficiency of aqueous sprays on foliage. Crop Protection, 19(1), 27-37. http://dx.doi.org/10.1016/S0261-2194(99)00079-4

[6] Massinon, M., \& Lebeau, F. (2012). Experimental method for the assessment of agricultural spray retention based on highspeed imaging of drop impact on a synthetic superhydrophobic surface. Biosystems Engineering, 112(1), 56-64. http://dx.doi.org/10.1016/i.biosystemseng.2012.02.005

[7] Miller, P. C. H., \& Ellis, B. (2000). Effects of formulation on spray nozzle perfo rmance for applications from ground-based boom sprayers. Crop Protection, 19(8), 609-615. http://dx.doi.org/10.1016/S0261-2194(00)00080-6

[8] Nuyttens, D., Baetens, K., De Schampheleire, M., \& Sonck, B. (2007). Effect of nozzle type, size and pressure on spray droplet characteristics. Biosystems Engineering, 97(3), 333-345. http://dx.doi.org/10.1016/i.biosystemseng.2007.03.001

[9] Taylor, W. A., Womac, A. R., Miller, P. C. H., \& Taylor, B. P. (2004). An attempt to relate drop size to drift risk. In International Conference on Pesticide Application for Drift Management, Waikoloa, Hawaii.

[10] Reichenberger, S., Bach, M., Skitschak, A., \& Frede, H. G. (2007). Mitigation strategies to reduce pesticide inputs into ground-and surface water and their effectiveness; A review. Science of the Total Environment, 384(1), 1-35. http://dx.doi.org/10.1016/i.scitotenv.2007.04.046

[11] Watson, E. J. (1964). The radial spread of a liquid jet over a horizontal plane. Journal of Fluid Mechanics, 20(03), 481-499. http://dx.doi.org/10.1017/S0022112064001367

Book

[12] Matthews, G., Bateman, R., \& Miller, P. (2014). Pesticide application methods. John Wiley \& Sons. http://dx.doi.org/10.1002/9780470760130 


\section{Appendix 1}

Grid convergence study

The uses of three mesh refinements for the test case study allow us to assess the discretization error. The relative error on the mean flow rate prediction far from the jet impact (whilst $r>10 \mathrm{a}$ ) is presented on the Figure 8 for each case. The predicted flow rate shows a monotonic convergence with the increase of cells. The computation of the order of the scheme leads to order of accuracy of 1.73 which is lower than the theoretical

$$
p=\frac{\log \left(\frac{\phi_{4 h}-\phi_{2 h}}{\phi_{2 h}-\phi_{h}}\right)}{\log (r)}
$$

where, $r$ is the refinement factor equal to 2 in this case and $\phi_{h} \phi_{2 h} \phi_{4 h}$ are respectively the fine, the normal and the coarse mesh.

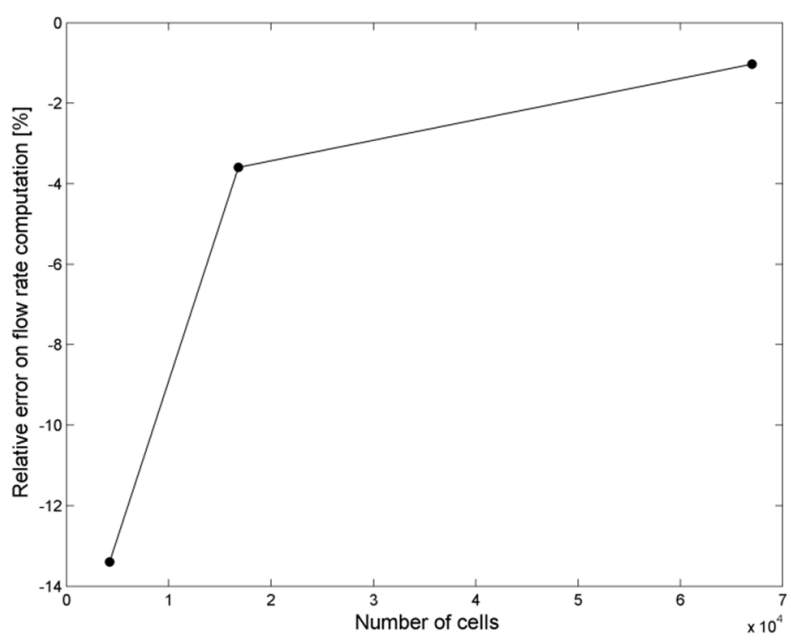

Figure 8. Flow rate computation error in respect with cell number 